\title{
The Use of Indigenous Medicine Among Women During Pregnancy and Labour in Rural Ghana
}

\author{
Beatrice Ayelyini ${ }^{1}$, Adadow Yidana ${ }^{2}$, Shamsu-Deen Ziblim ${ }^{2}$ \\ ${ }^{1}$ Department of Public Health, School of Allied Health Sciences, University for Development Studies, Tamale, Ghana \\ ${ }^{2}$ Department of Community Health and Family Medicine, School of Medicine and Health Science, University for Development Studies, \\ Tamale, Ghana
}

Email address:

beatriceayelyini@gmail.com (Beatrice A.), adadowy@yahoo.com (Adadow Y.), zshamsu72@gmail.com (Shamsu-Deen Z.)

\section{To cite this article:}

Beatrice Ayelyini, Adadow Yidana, Shamsu-Deen Ziblim. The Use of Indigenous Medicine Among Women During Pregnancy and Labour in Rural Ghana. Central African Journal of Public Health. Vol. 5, No. 3, 2019, pp. 120-128. doi: 10.11648/j.cajph.20190503.14

Received: February 28, 2019; Accepted: April 4, 2019; Published: May 15, 2019

\begin{abstract}
The increasing use of herbal medicine and related products in pregnancy has been noticed all over the world, however, the safety of these medicines becomes particularly important among pregnant women and children. In spite of the insufficient data to justify herbal use during pregnancy, exposure to herbal products in unspecified quantities among pregnant women is of great concern. This study assessed the determinants of herbal use (Kaligu-tim), a known local oxytocin and its impact on the maternal birth outcomes in a rural district in Ghana. Descriptive cross-sectional study design was used. It consisted of 339 women attending postnatal care and child welfare clinics across the district. Data collection was done using a structured questionnaire. The selection of respondents was done using a systematic sampling technique. The data were coded and entered into SPSS version 22.0 for analysis. From the study, $64.9 \%$ and $45.4 \%$ of respondents had used local oxytocin in their previous and current pregnancies respectively; 5.5\% did so during the first trimester, $26.8 \%$ in the second trimester and $67.7 \%$ in the third trimester. The study found a significant relationship between the use of herbal medicine and health servicerelated challenges, maternal age, the gestational term at delivery, parity of the respondents and mothers' ethnicity. Previous and current use of Kaligu-tim reduced birth weight by $26 \mathrm{~g}$ and $34.3 \mathrm{~g}$ respectively, though these were not statistically significant. However, the previous history of Kaligu-tim was significantly associated with perinatal asphyxia, postpartum haemorrhage, obstructed labour and foetal distress in their subsequent deliveries. It can be concluded that the use of this Kaligu-tim possesses a greater long term health challenge for mothers and their babies.
\end{abstract}

Keywords: Labour, Kaligu-tim, Pregnancy, Tolon, Postnatal, Oxytocin

\section{Background}

Indigenous cultures in low-income economies, particularly in Africa rely on the beneficial effects of herbal medicine during pregnancy and childbirth [1]. Over the past few decades, available research indicates that the use of indigenous medicine during pregnancy has grown considerably [2-4]. Indigenous medicines as used here denotes derivatives of nature, including herbs, animal and mineral products used to treat illnesses, including the management of symptoms of early pregnancy [5]. About $70 \%$ to $95 \%$ of the population in low-income economies rely on indigenous medicines for their health care needs [6]. According to Titilayo \& Fakeye [7], indigenous medicine in low-income economies plays an important role in the management of both mild and severe illnesses. It is also the view of others that the use of indigenous medicine is due to the dissatisfaction with conventional medicines in terms of its effectiveness, therapeutic outcome, and the perception of its inherent safety [8]. The increasing use of herbal medicine during pregnancy is a source of worry, especially the poor state of maternal health, a situation attributed to the inadequate access to reproductive health services [1]. Many expectant mothers, due to inadequate access to health care, rely on indigenous herbs during labour; which in fact, may have negative effects on both the mother and newborn [9]. It has also been observed that the use of herbal medicine during pregnancy and labour is fueled by cultural and personal beliefs regarding life and health [7-10]. As a result of these dynamics, the use of these medicines has become widespread 
for maternally related complaints even though the efficacy of some of them cannot be ascertained, [11-13].

A study conducted in a Ghanaian hospital revealed that about $50 \%$ of patients interviewed had used indigenous medicine prior to delivery [14]. The worrying situation, however, is that there is no established information on the pharmacologic interactions of the combined effects of herbal and orthodox medicines in the areas these medicines are used [11]. A survey conducted by the National Prescribing Service revealed that $65 \%$ of Australians who were interviewed had used one or more complementary medicine in the previous 12 months [7]. Again, a study in Ghana by Adusi-Poku et al. [11] showed that the use of herbal medicines was associated with a 30\% lower ongoing pregnancy and live birth rate during fertility treatment. Concerns have been expressed regarding the unregulated nature of some herbal medications $[15,16,7]$. Information regarding the safety and efficacy of the herbal medicines used during pregnancy is scanty. Some of these medicines are suspected to contain active ingredients that may find its way into the bloodstream of the baby and may cause harm to the unborn baby. In the Tolon District as well as the country as a whole, there is inadequate knowledge of herbal medicine, its usage and safety. Coupled with these factors, are the weak policy regulation and standard prescriptions of these medicines to its users including vulnerable pregnant women. This study assessed factors that influence the use of Kaligu-tim, a known local oxytocin and its impact during pregnancy and labour among women.

\section{Study Settings}

The study was conducted in the Tolon district in the Northern Region of Ghana. The district forms part of the twenty-six (26) districts of the region. It is bounded to the north by West Mamprusi, to the east by Kumbungu, to the south by Central Gonja and to the west by North Gonja districts/municipalities respectively. The district has a total population of eighty-four thousand seven hundred and twenty-four $(84,724)$ with an annual growth rate of $2.9 \%$. The district has a total of 157 communities with 314 Community Based Surveillance (CBS) volunteers. It has four (4) main sub-districts, namely; Tolon, Nyankpala, Wantugu and Lingbunga/Zantani sub-districts. It has twelve (12) health facilities.

\section{Methods and Design}

This study was a facility-based descriptive cross-sectional study, involving six health facilities. These health facilities were randomly sampled to represent peri-urban and rural populations. The study population comprised all lactating mothers aged 15 to 49 years. However, for the purposes of measuring the outcome variables, only women receiving their post-natal services were considered for the study. To be included in the study, the respondents may have been delivered by health professionals and/or by Traditional Birth Attendants (TBA). It was the belief of the researchers that some of the women may have used Kaligu-tim during the pregnancy or at the onset of labour before visiting the health facilities or before being attended to by the TBAs.

\subsection{Sampling and Sample Size Determination}

The Sample size was calculated using the formula:

$\mathrm{N}=\left[\mathrm{Z}^{2} \times \mathrm{P}(1-\mathrm{P})\right] / \mathrm{e}^{2}$ to arrive at a sample size of 339 .

Probability sampling technique was used to categorize the health facilities into clusters (Health Centers, Clinics, and CHPS Compounds). Due to the large sample size as compared with the district population, the study considered all the health centres and the clinic. However, a simple random technique was used to select three CHPS compounds out of the existing seven for the study. Population proportion to size was used to select respondents from the selected health facilities.

\subsection{Data Collection and Analysis}

Tools used in the data collection were questionnaires, and Likert scale checklist administered to midwives in the labour units at the Tolon health centre. Chi-square analysis was conducted to examine the association between socioeconomic and demographic, the outcome variables. Logistic regression analysis was used to estimate adjusted relative risk and their $95 \%$ confidence intervals for usage of Kaligu-tim and the effects. All data analyses were generated using SPSS software (Version 22).

\subsection{Ethical Considerations}

Consent of the respondents was sought through a written document for their approval. The aim of the study was explained in the consent form. Respondents were obliged to take part in the study voluntarily. Further consent was sought from the District Health Directorate and health facility incharges before the commencement of the study. Privacy and confidentiality of the actual source(s) of information obtained from the study were assured by not indicating the names of facilities and respondents who agreed to take part in the study. Names were not provided on the data collection tools and therefore no indications will be provided for someone to trace the source of information.

\section{Results}

\subsection{Socio-Demographic Characteristics}

The study engaged a total of 339 respondents with an average age of $29.89 \pm 6.08$ years. The youngest and oldest respondents in the study were 18 years and 45 years respectively (Table 1). From the study, the majority of the respondents were between the ages of 25-30 years. Almost all of the respondents were Dagombas (93.5\%). Again, 97.1\% of the respondents were married $(97.1 \%)$. On their educational background, as high as $74 \%$ had no formal education, $1.2 \%$ received were beneficiaries of non-formal education and $24.8 \%$ of them received some forms of primary $(16.5 \%)$, 
secondary (5.6\%) and tertiary (2.7\%) education. Again, respondents occupations were; housewives (34.2\%), smallscale traders $(33.3 \%)$, farmers $(29.5 \%)$ and formal sector workers $(2.9 \%)$. On the occupation of the husbands of the respondents, $58.7 \%$ were farmers, $21.8 \%$ were small-scale traders, $14.7 \%$ were working in the formal sector, and about
$4.7 \%$ of the husbands were artisans. On average, $66.4 \%$ of the households of respondents in the study earned a household net annual income of less than 500.00Ghc, $28.3 \%$ earned between 501.00-1000.00Ghe and only 5.3\% earned above $1000.00 \mathrm{Ghc}$.

Table 1. Socio-Demographic Characteristics of Respondents.

\begin{tabular}{|c|c|c|c|c|}
\hline SN & Variables & & Frequency & Per cent $(\%)$ \\
\hline \multirow[t]{4}{*}{1} & Age group of respondents: & & & \\
\hline & & $<24$ years & 70 & 20.6 \\
\hline & & $25-30$ years & 182 & 53.7 \\
\hline & & $>35$ years & 87 & 25.7 \\
\hline \multirow[t]{4}{*}{2} & Ethnicity: & & & \\
\hline & & Gonjas & 13 & 3.8 \\
\hline & & Dagombas & 317 & 93.5 \\
\hline & & Others & 9 & 2.7 \\
\hline \multirow[t]{3}{*}{3} & Marital status: & & & \\
\hline & & Singled & 10 & 2.9 \\
\hline & & Married & 329 & 97.1 \\
\hline \multirow[t]{6}{*}{4} & Educational level: & & & \\
\hline & & No Formal Education & 251 & 74 \\
\hline & & Non-formal Education & 4 & 1.2 \\
\hline & & Primary Education & 56 & 16.5 \\
\hline & & Secondary Education & 19 & 5.6 \\
\hline & & Tertiary Education & 9 & 2.7 \\
\hline \multirow[t]{5}{*}{5} & Occupations of respondents: & & & \\
\hline & & Housewives & 116 & 34.2 \\
\hline & & Farmers & 100 & 29.5 \\
\hline & & Small-scale Traders & 113 & 33.3 \\
\hline & & Formal Sector Workers & 10 & 2.9 \\
\hline \multirow[t]{5}{*}{6} & Occupation of respondents' husband: & & & \\
\hline & & Artisans & 16 & 4.7 \\
\hline & & Farmers & 199 & 58.7 \\
\hline & & Small-scale Traders & 74 & 21.8 \\
\hline & & Formal Sector Workers & 50 & 14.7 \\
\hline \multirow[t]{4}{*}{7} & Household estimated net annual income: & & & \\
\hline & & $<500.00 \mathrm{ghc}$ & 225 & 66.4 \\
\hline & & $501.00-1000.00 \mathrm{ghc}$ & 96 & 28.3 \\
\hline & & $>1000.00 \mathrm{ghc}$ & 18 & 5.3 \\
\hline
\end{tabular}

\subsection{Use of Herbal Medicine During Pregnancy and Labour}

Results from the study showed that the majority (85\%) of the respondents had knowledge of herbal medicine used during pregnancy (Table 2). Respondents who used herbal medicine during previous pregnancies were $64.9 \%$. However, it was reduced to $45.4 \%$ in their most recent pregnancy. About $31.2 \%$ of the respondents used a combination 2-3 types of the herbal medicine, $13 \%$ used a combination of four different types of the herbal medicine and about $55.8 \%$ used only one type of herbal medicine.

Table 2. Awareness and use of herbal medicine.

\begin{tabular}{|c|c|c|c|c|}
\hline SN & Variables Names & & Frequency & Per cent \\
\hline \multirow[t]{3}{*}{1.} & Awareness of Herbal Medicine: & & & \\
\hline & & No & 51 & 15 \\
\hline & & Yes & 288 & 85 \\
\hline \multirow[t]{3}{*}{2.} & Previous use of Herbal Medicine: & & & \\
\hline & & No & 119 & 35.1 \\
\hline & & Yes & 220 & 64.9 \\
\hline \multirow[t]{3}{*}{3.} & Current use of Herbal Medicine: & & & \\
\hline & & No & 185 & 54.6 \\
\hline & & Yes & 154 & 45.4 \\
\hline \multirow[t]{4}{*}{4.} & Combination of Herbal Medication used & & & \\
\hline & & Only one type of HM & 86 & 55.8 \\
\hline & & 2-3 types of $\mathrm{HM}$ & 48 & 31.2 \\
\hline & & $>4$ types of HM & 20 & 13 \\
\hline
\end{tabular}




\subsection{Reasons for Using Herbal Medicine}

From the study, $5.5 \%$ of the respondents used herbal medicine during the first trimester, $26.8 \%$ during the second trimester and $67.7 \%$ during the third trimester. Additionally, $89.1 \%$ used the medication specifically for labour-related reasons, $4.1 \%$ used it for postpartum period related concerns, and $4.4 \%$ used it in both labour and postpartum period for pregnancy-related challenges.

From Chi-square analysis, the age group of the respondents $(\mathrm{p}=0.040)$, educational level of respondents $(p=0.000)$, parity $(p=0.015)$, ethnicity $(p=0.001)$, gestational term at delivery $(\mathrm{p}=0.019)$, health-related challenge $(\mathrm{p}=0.018)$, distance to health facilities $(\mathrm{p}=0.000)$, and pregnancy-related conditions $(\mathrm{p}=0.003)$ were all significantly associated with the use of local oxytocin among the respondents in the study (Table 3). Univariate modelling analysis also showed a strong association between past and current use of herbal medicine among respondents. The results showed that primed mothers had a greater likelihood of using herbal medicine as compared with parity two or more. However, marital status of the respondents, occupation, household net income, gravidity, maternal condition, religious affiliation, and the perception of efficacy revealed no significant association with the use of the local oxytocin.

Table 3. Reasons for using Herbal Medicine.

\begin{tabular}{|c|c|c|c|c|c|c|}
\hline \multirow{2}{*}{ SN } & \multirow{2}{*}{ Variables Names } & \multirow{2}{*}{ Frequency } & \multirow{2}{*}{\multicolumn{2}{|c|}{ Percent }} & \multicolumn{2}{|l|}{ P-value } \\
\hline & & & & & Previous Use & Current Use \\
\hline \multirow[t]{4}{*}{1} & Age group of respondents & & & & & \\
\hline & & $<24$ years & 70 & 20.6 & 0009 & 0.040 \\
\hline & & $25-34$ years & 182 & 53.7 & 0.009 & 0.040 \\
\hline & & $>35$ years & 87 & 25.7 & & \\
\hline \multirow[t]{3}{*}{2} & Marital status: & & & & & \\
\hline & & Married & 329 & 97.1 & 0.504 & $0.357^{*}$ \\
\hline & & Singled & 10 & 2.9 & & \\
\hline \multirow[t]{4}{*}{3} & Mothers' ethnicity: & & & & & \\
\hline & & Gonja & 13 & 3.8 & & \\
\hline & & Dagombas & 317 & 93.5 & 0.001 & 0.221 \\
\hline & & Others & 9 & 2.7 & & \\
\hline \multirow[t]{6}{*}{4} & Educational level: & & & & & \\
\hline & & No Formal Education & 251 & 74.0 & & \\
\hline & & Non-formal Education & 4 & 1.2 & & \\
\hline & & Primary Education & 56 & 16.5 & $0.000^{*}$ & 0.000 \\
\hline & & Secondary Education & 19 & 5.6 & & \\
\hline & & Tertiary Education & 9 & 2.7 & & \\
\hline \multirow[t]{3}{*}{5} & Mothers' occupation: & & & & & \\
\hline & & Housewives & 116 & 34.2 & 1.000 & 0.909 \\
\hline & & Working Mothers & 223 & 65.8 & & \\
\hline \multirow[t]{5}{*}{6} & Respondents' husbands' occup & tion: & & & & \\
\hline & & Artisans & 16 & 4.7 & & \\
\hline & & Farmers & 199 & 58.7 & 0.151 & 0.291 \\
\hline & & Small-scale Traders & 74 & 21.8 & & \\
\hline & & Formal Sector Workers & 50 & 14.7 & & \\
\hline \multirow[t]{3}{*}{7} & Household estimated net annu & income: & & & & \\
\hline & & $<500.00 \mathrm{ghc}$ & 225 & 66.4 & 0.565 & 0.209 \\
\hline & & $>501.00 \mathrm{ghc}$ & 114 & 33.6 & & \\
\hline \multirow[t]{3}{*}{8} & Number of pregnancies by res & ondents: & & & & \\
\hline & & $<3$ pregnancies & 200 & 59 & 0.419 & 0.223 \\
\hline & & $>4$ pregnancies & 139 & 41 & & \\
\hline \multirow[t]{4}{*}{9} & Parity of respondents: & & & & & \\
\hline & & Primed & 65 & 19.2 & 0105 & 0015 \\
\hline & & 2-4th Child & 208 & 61.4 & 0.105 & 0.015 \\
\hline & & $>$ 5th Child & 66 & 19.5 & & \\
\hline \multirow[t]{4}{*}{10} & Gestational term at delivery: & & & & & \\
\hline & & $<32$ Weeks & 25 & 7.4 & 0050 & 0010 \\
\hline & & 33-37 Weeks & 129 & 38.1 & 0.059 & 0.019 \\
\hline & & $>38$ Weeks & 185 & 54.6 & & \\
\hline \multirow[t]{6}{*}{11} & Maternal condition experience & by respondents: & & & & \\
\hline & & Hypertension & 22 & 59.5 & & \\
\hline & & Diabetes & 1 & 2.7 & & \\
\hline & & Haemorrhage & 3 & 8.1 & 0.629 & 0.365 \\
\hline & & Eclampsia & 5 & 13.5 & & \\
\hline & & Other Conditions & 6 & 16.2 & & \\
\hline \multirow[t]{3}{*}{12} & Health-related reasons for usir & HM: & & & & \\
\hline & & Cost of Services at Health Facility & 16 & 10.4 & 0.018 & - \\
\hline & & Inaccessibility of Health Service at the point of illness & 21 & 13.6 & & \\
\hline
\end{tabular}




\begin{tabular}{|c|c|c|c|c|c|c|}
\hline \multirow{2}{*}{ SN } & \multirow{2}{*}{ Variables Names } & \multirow{2}{*}{ Frequency } & \multirow{2}{*}{\multicolumn{2}{|c|}{ Percent }} & \multicolumn{2}{|l|}{ P-value } \\
\hline & & & & & Previous Use & Current Use \\
\hline & & Distance to Health Facilities & 55 & 35.7 & & \\
\hline & & Lack of Medication at Health Facilities & 62 & 40.3 & & \\
\hline \multirow[t]{5}{*}{13} & Distance to neares & & & & & \\
\hline & & Very Short Distance $(1 \mathrm{~km})$ & 62 & 18.3 & & \\
\hline & & Short Distance $(5 \mathrm{~km})$ & 154 & 45.4 & 0.000 & 0.000 \\
\hline & & Far Distance (6-10km) & 94 & 27.7 & & \\
\hline & & Very Far Distance $(>10 \mathrm{~km})$ & 29 & 8.6 & & \\
\hline \multirow[t]{6}{*}{14} & Influence of pregn & ondition on the HM usage: & & & & \\
\hline & & A toothache & 3 & 0.9 & & \\
\hline & & Pains, Flu \& Stomach Problems & 230 & 67.8 & & \\
\hline & & Malaria \& RTI & 10 & 2.9 & 0.003 & - \\
\hline & & Swollen Feet, Back Pains etc. & 93 & 27.4 & & \\
\hline & & Digestive Problems & 3 & 0.9 & & \\
\hline \multirow[t]{3}{*}{15} & Spiritual/religious & f using HM: & & & & \\
\hline & & No & 129 & 83.8 & 1.000 & - \\
\hline & & Yes & 25 & 16.2 & & \\
\hline \multirow[t]{3}{*}{16} & Family or close fri & e on HM use: & & & & \\
\hline & & No & 26 & 16.9 & 1.000 & - \\
\hline & & Yes & 128 & 83.1 & & \\
\hline \multirow[t]{5}{*}{17} & Purpose of using $\mathrm{H}$ & & & & & \\
\hline & & To Induce Labor & 93 & 60.4 & & \\
\hline & & To protect Baby & 14 & 9.1 & 0.180 & - \\
\hline & & To Augment Labor & 44 & 28.6 & & \\
\hline & & To Induce Abortion & 3 & 1.9 & & \\
\hline
\end{tabular}

\subsection{Effects of Herbal Medicine on Pregnancy and Labour Outcomes}

The findings of the study revealed that $9.4 \%$ of the infants of the respondents in the study were underweight at birth (low birth weight), $21.2 \%$ were moderately asphyxiated, $16.5 \%$ of the respondents experienced postpartum haemorrhage, $9.1 \%$ obstructed labour at delivery, and $6.8 \%$ of the infants, experienced foetal distress and $1.8 \%$ also experienced stillbirth (table 4 ).

Table 4. Pregnancy Outcomes.

\begin{tabular}{lllll}
\hline SN & Variables & & Frequency & Per cent \\
\hline 1 & Birth Weights of Infants: & Low Birth Weight $(<2500 \mathrm{~g})$ & 32 & 9.4 \\
& & Normal Birth Weight $(>2500 \mathrm{~g})$ & 307 & 90.6 \\
2 & 5 Minutes Apgar Scores of Infants: & Moderate Birth Asphyxia $(<7$ score $)$ & 72 & 21.2 \\
& & Normal Infants $(>7$ score $)$ & 267 & 78.8 \\
3 & Post-partum Haemorrhage Status of respondents: & No & 283 & 83.5 \\
& & Yes & 56 & 16.5 \\
4 & Obstructed Labor in Delivery: & No & 308 & 90.9 \\
& & Yes & 31 & 9.1 \\
5 & Fetal Distress Status of Infants: & No & 316 & 93.2 \\
& & Yes & 23 & 6.8 \\
& & No & 333 \\
\end{tabular}

\subsection{Effects of Herbal Medicine on Birth Weight}

From the multiple logistic modelling, maternal characteristics did not show a statistical association with infants' birth weight of respondents in the study, with the exception of the parity of the respondents (table 5). The results showed that respondents of parity 5 and above are 13.6 times more likely to deliver infants with low birth weight than respondents of parity 2-3. Though the result was statistically significant, the association of parity with infants' birth weight was weak $(\mathrm{p}=0.049)$. However, from the univariate analysis, the result showed no significant association between parity and infants' birth weight of respondents. But the results showed that respondents of parity above 5 on the average had their infants weighed $74.5 \mathrm{~g}$, and $50 \mathrm{~g}$ heavier than infants of primed and respondents of parity 2-3 respectively. The use of Kaligu-tim in the previous pregnancies or delivery of the respondents did not show significant association $(\mathrm{p}=0.222)$ with the birth weight of the infants. Moreover, the univariate modelling showed no association between the previous use of local 
oxytocin and infants' birth weight but respondents with previous use of the oxytocin had their infants weighed $26 \mathrm{~g}$ heavier than infants of respondents with no previous history of local oxytocin $(\mathrm{p}=0.414)$. Again, the recent use of the local oxytocin had no significant association $(\mathrm{p}=0.915)$ with the birth weights of the respondents. Respondents with recent use of Kaligu-tim had an average infant birth weight of $2.695 \pm 0.275 \mathrm{~kg}$ as compared with $2.73 \pm 0.284 \mathrm{~kg}$ for infants' whose mothers had no current history of Kaligu-tim. The univariate modelling again showed that infants of respondents with a recent history of Kaligu-tim weighed $34.3 \mathrm{~g}$ lighter than infants whose mothers had no recent history of the local oxytocin, though the result was not statistically significant $(\mathrm{p}=0.263)$.

The multiple logistic modelling also showed that multiple uses of the local oxytocin were not associated with the birth weights of the infants of the respondents in the study. Respondents who used multiple combinations of 2-3 different types of the local oxytocin were 3.1 times more likely to deliver infants with low birth weight than respondents with the use of single oxytocin, though the results were not significant $(\mathrm{p}=0.255)$. However, univariate modelling showed a significant association between multiple combinations of local oxytocin and infants' birth weights. This relationship, however, was weaker, but respondents with 2-3 herbal combinations had infants weighed $111.8 \mathrm{~g}$ heavier than respondents who used single herbal oxytocin. Again, respondents with $\geq 4$ combinations had infants weighed $108.5 \mathrm{~g}$ heavier than respondents who used single herbal oxytocin.

Table 5. Factors influencing infant birth weights.

\begin{tabular}{|c|c|c|c|c|c|c|}
\hline Variables names & $\mathbf{X}$ & SD & Odds ratio & CI & Coeffi-cient & P-value \\
\hline \multicolumn{7}{|l|}{ Age groups of respondents: } \\
\hline$<24$ years & 2.693 & 0.363 & 0.5 & $-3.286,2.004$ & -0.641 & 0.635 \\
\hline$>35$ years & 2.766 & 0.274 & 0.4 & $-3.66,2.173$ & -0.744 & 0.617 \\
\hline \multicolumn{7}{|l|}{ Educational level of respondents: } \\
\hline \multicolumn{7}{|l|}{ Occupation of mothers: } \\
\hline Farmers & 2.718 & 0.257 & 1.9 & $-1.42,3.406$ & 0.993 & 0.420 \\
\hline \multicolumn{7}{|l|}{ Occupation of respondent husband: } \\
\hline $\begin{array}{l}\text { Small-scale trader } \\
\text { Household estimated net annual income }\end{array}$ & 2.715 & 0.242 & 2.4 & $-1.826,3.872$ & 1.023 & 0.428 \\
\hline $500.00 \mathrm{GHc}$ & 2.784 & 0.262 & 2.2 & $-1.957,3.069$ & 0.556 & 0.665 \\
\hline \multicolumn{7}{|l|}{ Number of pregnancies by respondents: } \\
\hline \multicolumn{7}{|l|}{ Parity of respondents: } \\
\hline Primed & 2.685 & 0.281 & 0.3 & $-0.4 \quad 3.887$ & 1.744 & 0.111 \\
\hline \multicolumn{7}{|l|}{ Awareness of herbal medicine: } \\
\hline Responded No & 2.773 & 0.358 & 0.1 & -6.5241 .396 & -2564 & 0.204 \\
\hline \multicolumn{7}{|l|}{ Previous use of herbal medicine: } \\
\hline \multicolumn{7}{|l|}{ Current use of herbal medicine in delivery: } \\
\hline \multicolumn{7}{|l|}{ Combination of herbal medicine used: } \\
\hline 2-3 types of herbal medicine & 2.758 & 0.327 & 3.1 & $-0.645 \quad 3.34$ & 1.088 & 0.255 \\
\hline$>4$ types of herbal medicine & 2.755 & 0.270 & 1 & -3.4823 .283 & 0.278 & 0.858 \\
\hline \multicolumn{7}{|l|}{ Stages in pregnancy respondents used HM } \\
\hline Second trimester & 2.724 & 0.284 & 1.1 & -3.7124 .003 & 0.145 & 0.941 \\
\hline Third trimester & 2.694 & 0.272 & 0.8 & -36233.5 & -0.062 & 0.973 \\
\hline \multicolumn{7}{|l|}{ The specific use of HM by respondents } \\
\hline Post-partum period & 2.66 & 0.253 & 0.1 & -5.1520 .443 & -2.354 & 0.099 \\
\hline \multicolumn{7}{|l|}{ The gestational term at delivery } \\
\hline \multicolumn{7}{|l|}{ Health-related reasons for using HM } \\
\hline Inaccessibility of care during illness & 2.681 & 0.278 & 1.3 & -3.3263 .453 & 0.063 & 0.971 \\
\hline Distance to health facility & 2.658 & 0.292 & 1.1 & $-2.348 \quad 2.43$ & 0.041 & 0.973 \\
\hline \multicolumn{7}{|l|}{ Distance to nearest health facility } \\
\hline Short distance $(5 \mathrm{~km})$ & 2.703 & 0.244 & 0.7 & -4.0353 .194 & -0.42 & 0.820 \\
\hline Far distance (6-10km) & 2.686 & 0.271 & 1.6 & -3.9094 .687 & 0.389 & 0.859 \\
\hline Very far distance $(>10 \mathrm{~km})$ & 2.703 & 0.304 & 0.3 & -6.7413 .521 & -1.61 & 0.539 \\
\hline $\begin{array}{l}\text { Influence of pregnancy-related conditio } \\
\text { use }\end{array}$ & 2.688 & 0.266 & 2.2 & -1.4353 .166 & 0.866 & 0.461 \\
\hline $\begin{array}{l}\text { Pain, flu and stomach problems } \\
\text { Malaria and RTI } \\
\text { Spiritual/religious connotations of using }\end{array}$ & 2.671 & 0.269 & 2.7 & -2.6845 .145 & 1.231 & 0.538 \\
\hline
\end{tabular}




\begin{tabular}{lllllll}
\hline Variables names & X & SD & Odds ratio & CI & Coeffi-cient & P-value \\
\hline $\begin{array}{l}\text { No } \\
\text { Family or close friends influences on HM use }\end{array}$ & 2.671 & 0.272 & 0.4 & -3.7772 .155 & -0.811 & \\
$\begin{array}{l}\text { No } \\
\text { Purpose of using herbal medicine }\end{array}$ & 2.7 & 0.297 & 0.9 & -2.7122 .213 & -0.249 & 0.843 \\
$\begin{array}{l}\text { To protect baby } \\
\text { To augment labour }\end{array}$ & 2.721 & 0.283 & 0.7 & -3.7373 .414 & -0.161 & 0.930 \\
\hline
\end{tabular}

\section{Discussion}

The prevalence of herbal medicine in pregnancy and/or labor has seen a steady decline over the past decade, from the $84 \%$ and $73 \%$ use of herbal medicine in the past and current pregnancies respectively, as contained in the $31^{\text {st }}$ Annual Meeting of Allied Health Professional Association (AHPA) in 2003 to $6.5 \%$ rate indicated by Adusi-Poku et al. [11]. The observed reduction in the use of herbal medication during pregnancy could be attributed to the increased access to primary health care services. The finding of the current study was about twice the rate of a multinational study by Deborah et al. [17] but by far higher than $4.3 \%$ in Sweden and much closer to the $69 \%$ rate in Russia. Again, across the Middle East, the finding was within the wide range of $22.3 \%$ to $82.3 \%$ [18]. In Sub-Saharan Africa again, the rate as contained in this current study was still found within the range of $30 \%$ to $70 \%$ as reported by Mamothena [19]. More specifically to the individual Sub-Saharan countries, the finding in the current study was more than double the rate of $20 \%$ in Northern Uganda conducted by Nyeko et al. [20], $32 \%$ in Zambia, $23 \%$ in Tanzania, and $12 \%$ in Nigeria by Ngoma \& Siachapa [21], and $12 \%$ in Kenya by Mothupi [22], but almost the same as 52\% in Zimbabwe and Malaysia $51.4 \%$ by Mothupi [22] and $80 \%$ in Kelantan Malaysia by Azriani \& Rahman [18]. However, the finding in the study is far more than seven times higher than the $6.5 \%$ rate indicated by Adusi-Poku et al. [11] in Ghana. On the combination of different types of herbal medication during pregnancy, $44.2 \%$ of the respondents used multiple local oxytocins as against $87 \%$ in Kelantan Malaysia by Adusi-Poku et al. [11]. The similarity between all these studies is that almost all of the studies were facility based cross-sectional surveys studies.

Many reasons account for the ever increasing use of herbal medicine in pregnancy and labour. These are related to challenges with access to health services, maternal factors and the socio-demographic environment of the respondents. Health service-related challenges included the cost, lack of access to health facilities at the point of need, distance to health care facilities, and unavailability of medication at healthcare facilities. Similarly, Mothupi [22] found healthrelated reasons to have promoted the use of herbal medicine in pregnancy among respondents in Nairobi, Kenya. As found in the current study, Malan \& Neuba [23] also indicated that pregnancy-related conditions were a significant determinant of the use of herbal medicine among pregnant women. Women with experience of pregnancy-related conditions such as nausea, vomiting and the like probably do not often regard such as a major health problem needing hospital attention and often resort to locally available medication for immediate relief. This could also be attributed to the notion that local medication had negligible side effects on pregnancy and was more effective for the treatment of these pregnancy-related conditions, particularly during the first trimester [23]. The current study also found a significant relationship between respondents' age groups and the use of herbal medicine among the respondents. Respondents older than 35years were less likely to use herbal medicine as compared with pregnant mothers less than 24years. This could be as a result of the fact that most of the pregnant women within the later age category are primed and are often overwhelmed with sudden physiological changes and hence resort to multiple medications including the herbal medicine for the management of these pregnancy-related conditions. Similarly to this finding, Namuddu et al. [24] found that older patients ( $\geq 39$ years) were less likely to use traditional herbal medicine but rather in HIV patients in Uganda. Contrarily to the finding in the current study, Gardiner et al. [25] found older years to have influenced the use of herbal medicine among adults in the United States. Again, among infertile women in Uganda, patients older than 30 years were more likely to use herbal medicine [26]. Contrarily to the finding by Deborah et al. [17], the current study found a significant relationship between herbal medication use and maternal age both as a categorical and continuous variable. Other findings also confirmed that educational status is a significantly important factor in the use of herbal medicine among pregnant mothers $[27,22,11]$. Similarly, Deborah et al. [17] found a significant association between maternal education and the use of herbal medicine in pregnancy but indicated that rather higher maternal education was associated with the use of herbal medicine, as also reported by Gardiner [25] in the United States. However, in Uganda, Kaadaaga et al. [26] found the use of herbal medicine to be associated with no education among women attending an infertility clinic. But unlike the current study, the Ugandan Study was among women with already health challenge who were skewed towards alternative medicines for their health problems. This is basically due to the fact that issues of fertility go beyond orthodox medicine in Africa culture to include both the traditional herbal medicine and spirituality [28].

Though the current study did not find any significant association between both previous and current use of Kaligutim on the birth weight of infants, it indicates that infants of respondents with a history of previous and current use of Kaligu-tim weighed $26 \mathrm{~g}$ and $34.3 \mathrm{~g}$ lighter respectively than their counterparts. The findings did not also indicate any significant associated with the use of multiple combinations 
( $\geq 1$ types of herbal medicines) and birth weight of infants. As indicated also by Jo et al. [29], this study found that adverse maternal and birth outcomes associated with the use of herbal medicine during pregnancy were not readily available in most studies. There was, therefore, very limited evidence available for direct comparison between the adverse maternal outcomes with the use of herbal medicine. Epidemiological studies in Finland also showed that the use of the herbal medicine "glycyrrhizin" was found to have reduced the birth weight of infants, though the result showed no statistical significance.

\section{Conclusion}

Health service-related challenges have been identified to have influenced the use of herbal medicine among pregnant women. These factors include the cost, lack of access to health facilities at the point of need, distance to health care facilities, and unavailability of medication at healthcare facilities. Also, the study found a significant relationship between herbal medication use and maternal age, the gestational term at delivery, parity of the respondents and mothers' ethnicity and education. Infants of mothers with a history of previous and current use of Kaligu-tim weighed $26 \mathrm{~g}$ and $34.3 \mathrm{~g}$ lighter respectively than their counterparts. It can be concluded that the use of this herbal medicine (Kaligu-tim) possess a greater long-term health challenge for mothers and their babies. Community health officers and midwives in the Tolon district must, therefore, intensify their public health campaigns against the use of the Kaligu-tim during pregnancy.

\section{Conflict of Interest}

There is no known conflict of interest.

\section{References}

[1] Attah, A. F., O’Brien, M., Johannes, K., Mubo, A. S., Moody, J. O., Smith, T. J., \& Gruber, C. W. (2012). Uterine contractility of plants used to facilitate childbirth in Nigeria, Ethnomedicine, Journal of Ethnopharmacology 143 (1) 377 382 .

[2] Eardley, S., Bishop, F. L., Prescott, P., Cardini, F., Brinkhaus, B., Santos-Rey, K., Vas, J., von Ammon, K., Hegyi, G., Dragan, S., Uehleke, B., Fonnebo, V., \& Lewith, G. (2012). A systematic literature review of complementary and alternative medicine prevalence in EU. Forsch Komplementmed, 19 (Suppl 2): 18-28.

[3] Holst, L., Wright, D., Haavik, S., \& Nordeng, H. (2009). The use and the user of herbal remedies during pregnancy. J Altern Complement Med, 15 (7): 787-792.

[4] Ramasubramaniam, S., Renganathan, L., Vijayalakshmi, G. \& Mallo-Banatao, M. V. (2015) Use of herbal preparations among parturient women: Is there enough evidence-A review of literature. International Journal of Herbal Medicine 2: 2026.
[5] Gichangi, P. (2014). Traditional medicines and their potential yeratogenic effects. Anatomy Journal of Africa, 3 (1), 1-3.

[6] Lu, Y., Hernandez, P., Abegunde, D. \& Edejer, T. (2011). The World Medicine Situation 2011, Geneva: Medicine expenditures, WHO.

[7] Titilayo, O. \& Fakeye, R. A. (2009). Attitude and use of herbal medicines among pregnant women in Nigeria, BioMed Central.

[8] Razak, M. G., Asante, F., Yeboah, J. Y., Kabila, A., Mensah, C. M., \& Lawrencia, P. S. (2016). Pulled in or pushed out? Understanding the complexities of motivation for alternative therapies use in Ghana; Int J. Qual Stud Health Well-being.

[9] Dika, H., Dismas, M., Iddi, S., \& Richard, R. (2017). Prevalent use of herbs for reduction of labour duration in Mwanza, Tanzania: are Obstetricians aware? Tanzania Journal of Health Research, 19 (2) 1-8.

[10] Women's, T. (2013). Herbal and Traditional Medicines in Pregnancy. the women's royal hospital. Victoria Australia, 13. The Royal Women's Hospital Fact Sheet / www.thewomens.org.au

[11] Adusi-Poku, Y., Vanotoo, L., Detoh, E. K., Oduro, J., Nsiah, R. B. \& Natogmah, A. Z. (2015). Type of herbal medicines utilized by pregnant women attending ante-natal clinic in Offinso north district: are orthodox prescribers aware? Ghana Medical Journal, 49 (4). 227-232. http: //dx.doi.org/10.4314/gmj.v49i4.2

[12] Frawley, J., Adams, J., Steel, A., Broom, A., Gallois, C., \& Sibbritt, D. (2015). Women use and Self-prescription of herbal medicine during pregnancy, an examination of 1,835 pregnant women. Women Health Issues, 25 (4): 396-402.

[13] Holst, L., Nordeng, H., \& Haavik, S. (2008). Use of herbal drugs during early pregnancy in relation to maternal characteristics and pregnancy outcome. Pharmacoepidemiol Drug Saf, 17 (2): 151159 .

[14] Addo, V. N. (2007). Herbal Medicines: Socio-demographic Characteristics and Pattern of Use by Patients in a Tertiary Obstetrics and Gynaecology Unit. J Sci Technol, 27 (3):149160 .

[15] Uzzolin, L. \& Benoni, G. (2009). Safety issues of phytomedicines in pregnancy and paediatrics. In: Herbal drugs: Ethnomedicine to modern medicine. Edn. springer, 381-396.

[16] John, L. J. \& Nisha, S. (2015). Herbal Medicine Use during Pregnancy: A review from the Middle East, Oman Medical Journal, 30 (4): 229-236.

[17] Deborah, A. K., Angela, L., Gideon K., \& Hedvig, N. (2013). Herbal medicine use in pregnancy: results of a multinational study; BMC Complementary and Alternative Medicine. University of Toronto, M5G 1X8 Ontario, Canada, P: 2-10.

[18] Azriani, A. \& Rahman, Z. A. (2008). The use of herbal medicines during pregnancy and perinatal mortality in Tumpat district, Kelantan, Malaysia. Southeast Asian j trop med public health, 38 (6), 1150-1158.

[19] Mamothena, C. M. (2014). Use of herbal medicine during pregnancy among women with access to public healthcare in Nairobi, Kenya: a cross-sectional survey, BMC Complement Altern Med, 14: 432. doi: 10.1186/1472-6882-14-4. 
[20] Nyeko, R., Tumwesigye, M. N., \& Halage, A. A. (2016). Prevalence and factors associated with use of herbal medicines during pregnancy among women attending postnatal clinics in Gulu district, Northern Uganda. BMC Pregnancy and Childbirth, 16:296DOI 10.1186/s12884-0161095-5 https:

//www.ncbi.nlm.nih.gov/pmc/articles/PMC5053208/

[21] Ngoma, M. C. \& Siachapa, B. (2017). Use of Herbal Medicines to Induce Labour by Pregnant Women: A Systematic Review of Literature. JO J. Nurse Health Care, 2 (3) 1-5. DOI: 10.19080/JOJNHC.2017.02.555590

[22] Mothupi, M. C. (2014). Use of herbal medicine during pregnancy among women with access to public healthcare in Nairobi, Kenya: a cross-sectional survey. BMC Complementary and Alternative Medicine, 1-8.

[23] Malan, D. F. \& Neuba, D. F. R. (2011). Traditional Practices and Medicinal Plants Use during Pregnancy by Anyi-Ndenye Women (Eastern Côte d'Ivoire) Afr J Reprod Health, 15 [1]: 85-93.

[24] Namuddu, B., Kalyango, N. J., Karamagi, C., Mudiope, P., Sumba, S., Kalende, H., Wobudeya, E., Kigozi, K. B. \& Waako, P. (2011). Prevalence and factors associated with traditional herbal medicine use among patients on highly active antiretroviral therapy in Uganda. BMC Public Health, 11:855. 2-9 http: //www.biomedcentral.com/1471-2458/11/855
[25] Gardiner, P., Graham, R., Legedza A. T. R., Ahn, A. C., Eisenberg, D. M., \& Phillips, R. S. (2007). Factors associated with herbal therapy use by adults in the United States, Herbal Therapy Use in the United States, Alternative Therapy, 13 (2). 22-29.

[26] Kaadaaga, F. H., Ajeani, J., Ononge, S., Alele, E. P., Nakasujja, N., Manabe, C. Y., \& Kakaire, O. (2014). Prevalence and factors associated with use of herbal medicine among women attending an infertility clinic in Uganda. $B M C$ Complementary and Alternative Medicine, 14 (27) http: //www.biomedcentral.com/1472-6882/14/27 retrieved on $17 / 12 / 2017$.

[27] Tamuno, I., Omole-Ohonsi, A., \& Fadare, J. (2011). Use of Herbal Medicine among Pregnant Women Attending a Tertiary Hospital in Northern Nigeria. Internet J of Gyn and Obstet, 15 (2). doi:10.5580/2932.

[28] Ondicho, J., Ochora, J., Matu, E., \& Mutar, J. (2015). Factors associated with use of herbal medicine among patients in herbal clinics in Gucha district, Kenya, The 2015 JKUAT Scientific Conference, Basic and Applied Sciences, 174-187.

[29] Jo, J., Haeng, S., Moo, J., Lee, H., \& Jun, S. (2016). European Journal of Integrative Medicine Use and safety of Korean herbal medicine during pregnancy: A Korean medicine literature review. European Journal of Integrative Medicine, 8 (1), 4-11. https: //doi.org/10.1016/j.eujim.2015.10.008. 